www.jmscr.igmpublication.org

Impact Factor (SJIF): 6.379

Index Copernicus Value: 79.54

ISSN (e)-2347-176x ISSN (p) 2455-0450

crossrefDOI: https://dx.doi.org/10.18535/jmscr/v6i11.24

Journal Of Medical Science And Clinical Research

IGM Publication

An Official Publication of IGM Publication

\title{
A Paper on Clinical Significance of Cervical Insufficiency in Bad Obstetric History
}

\author{
Authors \\ Dr Vinodkumar Suresh Basavaradder ${ }^{1}$, Dr Ratana Usham ${ }^{2}$ \\ Prof. Ng. Indrakumar Singh ${ }^{3}$ \\ ${ }^{1}$ Postgraduate Trainee, ${ }^{2}$ Assistant Professor, ${ }^{3}$ Prof \& Head of the Department, \\ Obstetrics and Gynaecology, JNIMS, Imphal, Manipur, India
}

\begin{abstract}
Background: Death of a fetus in-utero or at birth has always been devastating and painful experience for the mother and of concerned in clinical practice. Perinatal mortality remains a challenge in the care of pregnant women worldwide particularly for those who had history of adverse outcome in previous pregnancies. For the modern obstetrician, the cervical insufficiency represents a controversial problem as the treatment modalities for the same have changed with time since its description and there is no clear cut diagnosing criteria for the diagnosis and hence there is need for the presumptive diagnosis of cervical insufficiency in women with recurrent pregnancy losses after ruling out all possible causes and usefulness of cervical encerclage operation in management of cervical insufficiency.

Result: The three pregnant women who presented to Gynaec OPD at around 16-18 weeks of gestation with history of recurrent pregnancy loss during $2^{\text {nd }}$ trimester and early $3^{\text {rd }}$ trimester were provisionally diagnosed to have cervical insufficiency based on clinical history and in all three women prophylactic encerclage procedure was done. Two were delivered at term and one at 34 weeks of gestation. All three newborn babies were healthy with no complications postpartum.

Conclusion: Recurrent miscarriages may increase psychological stress. Managing recurrent pregnancy loss should be individualised. By using the correct weapon, required target can be achieved. In our case series all patients provisionally diagnosed to have cervical insufficiency, were treated with prophylactic encerclage (McDonald procedure). Above said intervention led to fruitful outcome of all three pregnancy.

Keywords: Cervical insufficiency, Cervical circlage, McDonald procedure, Shirodkar procedure.
\end{abstract}

\section{Introduction}

Recurrent pregnancy loss is a frustrating and challenging problem for couples and clinicians. Cervical insufficiency may be present in up to $1 \%$ of obstetric population. The classic history that raises the suspicion of cervical insufficiency is that of recurrent mid-trimester pregnancy losses. In this condition the cervix begins to dilate (and not by initiation of contraction) and there is inability to hold the weight of pregnancy leading to bulging of amniotic membranes into the vaginal canal, resultant rupture, fetal loss /preterm birth. Cervical incompetence not only poses a management dilemma to the modern day obstetrician but is also a source of anxiety for the couple with recurrent pregnancy wastage. It is 
most important cause of recurrent spontaneous mid-trimester abortion, it is thought to be responsible for approximately $15 \%$ of habitual immature deliveries in the $2^{\text {nd }}$ trimester of pregnancy. The diagnosis of cervical insufficiency is exclusive because of lack of uniform diagnostic criteria, diagnostic test and also the role of cervical cerclage and indications for it remain illdefined and controversial. Aim of this study is to determine the presumptive diagnosis of cervical insufficiency in recurrent pregnancy loss and usefulness of cervical cerclage operation and to learn from the past pregnancies and ensure a more favourable outcome in the current or future pregnancy.

\section{Case Series}

\section{Case 1}

A 26 year old Gravida 4, Para 1, Preterm 3 with no living fetus $\left(\mathrm{G}_{4}-\mathrm{P}_{1+3+0+0}\right)$ bearing IP number 61606 presented with previous history of 3 spontaneous preterm delivery, $1^{\text {st }}$ and $2^{\text {nd }}$ pregnancy at 7 month of gestation and $3^{\text {rd }}$ pregnancy at 8 months of gestationto Gynaec OPD, JNIMS, Imphal at $16^{\text {th }}$ week of gestation. After ruling out congenital anomalies prophylactic cervical cerclage was done at $18^{\text {th }}$ week of gestation based on clinical history. Patient was observed and followed upto term, at 37 weeks of gestation cerclage removed and LSCS done on patient request. A healthy female term fetus weighing $2.9 \mathrm{~kg}$ delivered by $\mathrm{C}$-section. The newborn was healthy and was discharged with no complications.

\section{Case 2}

A 39 year old Gravida 6, Para 1, Preterm 4, Abortion 1 with no living fetus $\left(\mathrm{G}_{6}-\mathrm{P}_{1+4+1+0}\right)$ bearing IP number 58396 presented with previous history of 1 spontaneous preterm delivery at $8^{\text {th }}$ month, Male fetus, IUD and 4 abortions $\left(2^{\text {nd }}, 3^{\text {rd }}\right.$ and $4^{\text {th }}$ pregnancy at $6^{\text {th }}$ month of gestation and $5^{\text {th }}$ pregnancy aborted at $4^{\text {th }}$ month of gestation)to Gynaec OPD, JNIMS, Imphal at $18^{\text {th }}$ week of gestation. After ruling out congenital anomalies, prophylactic cervical cerclage was done at $18^{\text {th }}$ week of gestation based on clinical history. Patient was observed and followed up in the hospital at 34 weeks patient had PV leaking followed by preterm delivery. A healthy preterm male fetus delivered by NVD weighing $1.7 \mathrm{~kg}$. The newborn was healthy and admitted to NICU for 1 week and was discharged with no complications. And follow up evaluation showed no neurological impairment.

\section{Case 3}

A 39 year old Gravida 9, Para 1, Preterm 0, Abortion 7 with 1 living fetus $\left(\mathrm{G}_{9}-\mathrm{P}_{1+0+7+1}\right)$ bearing IP number 65958 presented with previous history of 7 spontaneous abortions, $1^{\text {st }}$ pregnancy was full term, NVD. All remaining pregnancies had spontaneous abortion around 16-20 weeks to Gynaec OPD, JNIMS, Imphal at $16^{\text {th }}$ week of gestation. After ruling out congenital anomalies prophylactic cervical cerclage was done at $18^{\text {th }}$ week of gestation based on clinical history. Patient was observed and followed up upto term, at 37 weeks cerclage removed, A healthy female term fetus weighing $3.1 \mathrm{~kg}$ delivered by NVD. The newborn was healthy and was discharged with no complications.

In all 3 cases the clinical diagnosis of cervical insufficiency was made based on history as it is the most common cause of recurrent pregnancy loss during $2^{\text {nd }}$ trimester and early $3^{\text {rd }}$ trimester.

\section{Discussion}

When there is previous history of fetal or neonatal loss there is a possibility of effects of these losses in the present pregnancy, this is called pregnancy with bad obstetric history. There is a possibility that the next pregnancy may be affected by the same complication and if same type of complication occurs in two pregnancies the chance of recurrence in third pregnancy is very high so pregnancy with Bad obstetric history is considered as high risk pregnancy. Risk factors for pregnancy losses are Fetal anomalies, Chromosomal anomalies, Uterine anatomical defects, Leiomyomas, Incompetent cervix, 
Placental causes like abruption, placenta previa, Defective spiral artery transformation, Chorioamnionitis and Maternal disorders like Autoimmune disorders, Infections, Metabolic disorders. Cervical insufficiency causes second trimester pregnancy loss or preterm delivery in up to $2 \%$ of all pregnancies, but responsible for only $8-9 \%$ of all preterm births compared to 40 $50 \%$ from spontaneous preterm labour and 20$30 \%$ from preterm prelabour rupture of membranes (PPROM $)^{1,2}$. Cervical insufficiency also known as cervical incompetence is defined by (ACOG) as the inability of the uterine cervix to retain a pregnancy in the second trimester, in the absence of uterine contractions. Classic cervical insufficiency is diagnosed based on history of recurrent $2^{\text {nd }}$ and early $3^{\text {rd }}$ trimester fetal loss following painless cervical dilatation or prolapse or rupture of membrane and expulsion of live fetus despite of minimal uterine contraction ${ }^{3}$. In the absence of recurrence, single classical history of cervical insufficiency is diagnosed after exclusion of other possible causes of preterm delivery. In the absence of second or early third trimester fetal loss is incorrect to use the term cervical insufficiency in connection with short or traumatised cervix alone. The cervix is unique and complex structure, Embryologically, the body and cervix of the uterus are derived from fusion and recanalization of the paramesonephric (Mullerian) ducts, a process that is complete by the 5th month of intrauterine development. Histologically, the cervix consists of fibrous connective tissue, muscle, and blood vessels. Muscular connective tissue constitutes approximately $15 \%$ of the cervical stroma, but is not uniformly distributed throughout the cervix, constituting more in upper part when compared to lower part of cervix. Conversely, the fibrous connective tissue content of the cervical stroma increases as one moves from the external os to the uterine corpus, and it this component that is believed to confer tensile strength to the cervix. Defects in tensile strength are thought to lead to premature cervical dilatation and pregnancy loss. In pregnancy, the normal cervical length is between $3-4 \mathrm{~cm}$. The function of the cervix during pregnancy depends on the regulations of connective tissue metabolism. Collagen is the principal component in the cervical matrix, others are Proteoaminoglycans, Elastin and Glycoproteins i.e., Fibronectin. The biochemical events implicated in Cervical ripening are Decrease in total collagen content, Increase in collagen solubility and Increase in collagenolytic activity. The cervical incompetence is a specific entity involving not just an abnormality or defect of cervical collagen, but also due to either absence of the usual musculature (congenital) or Injury or damage to the cervical musculature caused by previous trauma.

Aetiologic factors for cervical insufficiency includes congenital causes like congenital weakness of the internal os (histologic defect is increased smooth muscle fibres, decreased collagen/elastic fibres, inherently weak muscularcervix), Diethylstilbestrol (DES) exposure in utero ${ }^{4}$, Connective tissue disorder (Ehlers-Danlos Syndrome, Marfan syndrome ${ }^{5}$ ), Congenital mullerian duct abnormalities (Bicornuate and septate uterus; Short, hypoplastic cervix. Acquired causes like Trauma to the cervix, overzealous dilatation and curettage especially 2nd trimester, cone biopsy or loop electrosurgical excision procedures, cryotherapy ${ }^{6}$, cervical amputation (Trachelectomy), difficult or instrumental vaginal delivery (cervical laceration), Extension of the uterine incision into the cervix during the Caesarean ${ }^{7}$. Infections like Bacterial Vaginosis ${ }^{8}$, chlamydia, Group B streptococcus (GBS), mycoplasma and gonorrhoea.

Diagnosis of cervical insufficiency based on history, symptoms and investigations. Classical presentation is recurrent spontaneous mid trimester miscarriage, painless cervical dilatation, protrusion of membranes into the vagina, rupture of the membranes and expulsion of fetus. Strongest evidence for diagnosis of Cervical Incompetence is lack of any other causes for recurrent pregnancy loss the detailed history comprising any complication during previous 
pregnancy, duration of pregnancy at the time of death of fetus, preterm delivery, intranatal complication, any congenital fetal defect in previous pregnancy, history of medical disorders, family history of DM, HTN, delivery of malformed babies are enquired. Investigations required to rule out other causes for recurrent pregnancy loss are Hemoglobin, Blood group and Rh typing, Blood sugar level, Thyroid profile, tests for antiphospholipid antibody syndrome, ultrasonography, karyotyping. Investigations for diagnosing cervical insufficiency in non pregnant women are Easy passage of a size 8 Hegar's/ Pratt's Dilator size $15-17^{9}$, Foley's catheter traction test ${ }^{10}$, Hysterosalpingography showing Dilated internal Os $>8 \mathrm{~mm} /$ Widened Isthmus (Funnel/Inverted Bishop's cap) and in pregnant women Weekly or forth nightly cervical assessment-softening, effacement and dilatation. Serial Ultrasound assessment of the lower uterine segment and cervix.Cervical stress test usually done at 15-24weeks which shows increasing transfundal intrauterine pressure while monitoring cervical length and the appearance of funnelling. "Funneling" (Y,V,U shape) of the internal cervical os is the transvaginal ultrasonographic appearance of cervical incompetence. Funneling is the separation of the internal os from the two side walls of the upper end of the cervicalcanal. Cervical length analysis using transvaginal sonography is safe, highly reproducible, and more predictive than transabdominal sonographic screening (ACOG 2012b). TVS finding of cervical canal length $<2.5 \mathrm{~cm}^{11}$ and Diameter of the Internal Os $>15 \mathrm{~mm}$ in the $1 \mathrm{st}$ trimester $\&>20 \mathrm{~mm}$ in the 2nd trimester are strong predictors of preterm birth $^{12}$.

Cervical incompetence managed by medical and surgical methods. Surgical method like Cervical Cerclage, can be Prophylactic (Elective) or Emergency (Salvage/Rescue). The success rate of cerclage procedure can be high when done early in pregnancy, after 13 weeks prior to 18 weeks but usually done between 14-16weeks. Before cerclage procedure it is advisable to confirm a living fetus and to exclude major fetal anomalies and infections. Currently, there are five different techniques for performing cervical cerclage, McDonald procedure, Shirodkar operation, Wurm procedure (Hefner cerclage), Trans abdominal cerclage and Lash procedure. The two most common are McDonald \& Shirodkar procedures. In McDonald s procedure ${ }^{13}$ the junction between the anterior vaginal rugose and smooth cervical mucosa is identified. Four bites of the suture are placed circumferentially to form a purse string (1st bite before 12o'clock and last just after 120 'clock). Now days the knot placed in $6 \mathrm{O}$ clock position to avoid irritation to bladder. Shirodkar procedure ${ }^{14}$ involves placement of a non-absorbable suture i.e., Fascia lata, Silk, Nylon or Mersilene tape around the cervix at the internal os. The junction between the anterior vaginal wall rugose with the smooth cervical mucosa is identified. Transverse incision $2 \mathrm{~cm}$ long is made at the junction \& the bladder bluntly dissected until the uterovesical peritoneum is identified. An atraumatic needle is passed submucosally in the cervix posteriorly and knotted. The suture lies completely beneath vaginal and cervical mucosa. The vaginal mucosa thereafter sutured anteroposteriorly. Original idea was to leave stitch in-situ and opt for Caesarean section. In modified shirodkar procedure the delivery does not necessarily have to be by Caeserean, nor the suture left intact. Both the McDonald and Shirodkar procedures cervical sutures are equally effective as a vaginal approach to cervical cerclage. McDonald suture is generally easier to perform with no major difference in success. Both initially started suturing with catgut, but Shirodkar turned to fascia lata and McDonald turned to silk as they realized the importance of a permanent cervical support. One significant difference, at present day is the use of mersilene tape as the suture material. Wurm procedure (Hefner cerclage $)^{15}$ is done when incompetent cervix is diagnosed later in pregnancy. It has an added benefit when there is a little cervix to work with. The cerclage can be removed at term. Usually 
done with $U$ or mattress suture and is of benefit when there is minimal amounts of cervix left. Trans abdominal cerclage ${ }^{16}$ is typically reserved for patients with anatomic limitations or those with a history of failure of a transvaginal cerclage. Complication of cerclage procedure include early complications like Infections (Chorioamnionitis, Vulvo vaginitis), Bleeding, Anaesthetic complications, Accidental rupture of fetal membranes, Premature Labour, Maternal Death in the presence of sepsis due to PROM. Deep Cervical Laceration, Puerperal Pyrexia, Urinary tract infection. And late complications like Fistula Formation, Cervical Stenosis, Scarring -Cervical Dystocia in Labour, Precipitate Labour, Preterm Deliveries. Contraindications for procedure include Uterine contractions, Uterine bleeding, Chorioamnionitis, Premature rupture of membranes, Fetal anomaly incompatible with life. Medical treatment options available for cervical incompetence are placement Hodges pessaries, Baylor Balloons and Progesterone supplementation. A cervical pessary is thought to alter the axis of the cervical canal and displace the weight of pregnant uterus away from the cervix. ACOG recommends that women with a prior spontaneous preterm birth should be offered Progesterone supplementation starting at 1624 weeks gestation and continuing upto 36 weeks gestation in order to reduce the risk of recurrent preterm birth.

\section{Conclusion}

Recurrent miscarriages may increase psychological stress on couples and may even lead to broken marriages and relationships, it is thus important to pay attention to the issue. Managing recurrent pregnancy loss should be individualised, detailed history taking is required to identify targeted risk factors. Proper documentation of the worked out investigation results, will ease the subsequent antenatal care. By using the correct weapon, required target can be achieved. In our case series all patients provisionally diagnosed to have cervical insufficiency, were treated with prophylactic encerclage (McDonald procedure). Above said intervention led to fruitful outcome of all three pregnancy.

\section{References}

1. Norwitz ER RJ, Greene M. Cervical Cerclage-elective and emergent. ACOG Update. 1999;24:1-11.

2. Slattery MM, Morrison JJ. Preterm delivery. Lancet. 2002;360 (9344):14891497.

3. Easterday CL, Reid DE. The incompetent cervix in repetitive abortion and premature labor. N Engl J Med. 1959,260:687-690.

4. Kaufman RH. Structural changes of the genital tract associated with in utero exposure to diethylstilbestrol. Obstet Gynecol Annu. 1982;11:187-202.

5. Anum EA, Hill LD, Pandya A, Strauss JF. Connective tissue and related disorders and preterm birth: clues to genes contributing to prematurity. Placenta. 2009;30(3):207-215.

6. Berghella V TJ, Kuhlman K, Weiner S, Bolognese RJ, Wapner RJ. Cervical ultrasonography compared with manual examination as a predictor of preterm delivery. Am J Obstet Gynecol. 1997;177(4):723-730.

7. Vyas NA, Vink JS, Ghidini A. Risk factors for cervical insufficiency after term delivery. Am J Obstet Gynecol. 2006;195 (3):787-791.

8. Donders GG, Van Calsteren C, Bellen G. Association between abnormal vaginal flora and cervical length as risk factors for preterm birth. Ultrasound Obstet Gynecol. 2010.

9. Page EW. Incompetent internal os of the cervix causing late abortion and premature labor; technic for surgical repair. Obstet Gynecol 1958;12:509-515.

10. Bergman P, Svennerud S. Traction test for demonstrating incompetence of the 
internal os of the cervix. Int $\mathrm{J}$ Fertil 1957;2:163-167.

11. Goldenberg RL IJ, Miodovnik M, Van Dorsten JP. The preterm prediction study: risk factors in twin gestations. National Institute of Child Health and Human Development Maternal-Fetal Medicine Units Network. Am J Obstet Gynecol. 1996; 175:1047-1053.

12. Heath VC, Southall TR, Souka AP, Elisseou A, Nicolaides KH. Cervical length at 23 weeks of gestation: prediction of spontaneous preterm delivery. Ultrasound Obstet Gynecol. 1998;12:312-317.

13. McDonald IA. Suture of the cervix for inevitable miscarriage. J Obstet Gynaecol Br Emp. 1957;64:346-350.

14. Shirodkar VN. A new method of operative treatment for habitual abortions in the second trimester of pregnancy. Antiseptic 1955;52 299-300

15. Hefner JD, Patow WE, Ludwig JM, JR. A new surgical procedure for the correction of the incompetent cervix during pregnancy. The Wurm procedure. Obstet Gynecol 1961;18:616-20.

16. Benson RC, Durfee RB. Trans abdominal cervico uterine cerclage during pregnancy for the treatment of cervical incompetency. Obstet Gynecol 1965;25:145-155. 